\title{
Bone Forming Capacity of Cell- and Growth Factor-Based Constructs at Different Ectopic Implantation Sites
}

\author{
Jinling Ma, ${ }^{1,2}$ Fang Yang, ${ }^{1}$ Sanne K. Both, ${ }^{1}$ Henk-Jan Prins, ${ }^{3,4}$ Marco N. Helder, ${ }^{5}$ Juli Pan, ${ }^{2,6}$ \\ Fu-Zhai Cui, ${ }^{7}$ John A. Jansen, ${ }^{1}$ Jeroen J.J.P. van den Beucken ${ }^{1}$ \\ ${ }^{1}$ Department of Biomaterials, Radboud University Medical Centre, Nijmegen, the Netherlands \\ ${ }^{2}$ Department of VIP service, Beijing Stomatological Hospital, Capital Medical University, Beijing 100050, China \\ ${ }^{3}$ Department of Oral Cell Biology, Academic Centre for Dentistry Amsterdam, University of Amsterdam and VU University \\ Amsterdam, Amsterdam, the Netherlands \\ ${ }^{4}$ Department of Oral and Maxillofacial Surgery, VU University Medical Centre/ACTA, Amsterdam, the Netherlands \\ ${ }^{5}$ Department of Orthopedic Surgery, VU University Medical Centre, Amsterdam, the Netherlands \\ ${ }^{6}$ Department of Oral and Maxillofacial Surgery, Beijing Stomatological Hospital, Capital Medical University, Beijing, 100050, \\ China \\ ${ }^{7}$ Department of Materials Science and Engineering, State Key Laboratory of New Ceramics and Fine Processing, Tsinghua \\ University, Beijing 100084, China
}

Received 4 December 2013; revised 14 March 2014; accepted 4 April 2014

Published online 22 April 2014 in Wiley Online Library (wileyonlinelibrary.com). DOI: 10.1002/jbm.a.35192

\begin{abstract}
The aim of this study was to compare the effect of implantation site (i.e., subcutaneous, SO vs. intramuscular, IM) on bone forming capacity of cell-based and growth factor-based scaffolds in athymic nude rats after an implantation period of 8 weeks. Cell-based scaffolds consisted of porous hydroxyapatite/tricalcium phosphate (HA/TCP) scaffolds seeded with either human adipose tissue-derived mesenchymal stem cells (AT-MSCs) only or both AT-MSCs and human umbilical vein endothelial cells (HUVECs), which were precultured in osteogenic medium for 7 days. Growth factorbased scaffolds consisted of porous HA/TCP scaffolds with 20 $\mu \mathrm{g}$ preadsorbed bone morphogenetic protein-2 (BMP-2). Histological and histomorphometrical analysis were used to assess bone formation. A differentiation experiment was performed in parallel to compare the in vitro osteogenic capacity of cell-based scaffolds. The results showed that cell-based scaffolds showed evident osteogenic differentiation in vitro, with only marginal differences between AT-MSCs only and AT-MSCs/HUVECs. In vivo, none of the cell-based scaffolds
\end{abstract}

showed bone formation, irrespective of the site of implantation. In contrast, all growth factor-based scaffolds showed bone formation at both implantation sites without differences in the amount of formed bone. In conclusion, the results of this study demonstrated that the bone forming capacity of HA/TCP scaffolds with pre-adsorbed BMP-2 was equal at different ectopic implantation sites. Further, despite obvious in vitro osteogenic differentiation of AT-MSCs and AT-MSCS/ HUVECs on HA/TCP scaffolds, no bone formation of these cell-based scaffolds was observed in vivo. This indicates further investigation on bone formation mechanisms of ATMSCs is needed before AT-MSCs can be used as a cytotherapeutic treatment in clinics. ( 2014 Wiley Periodicals, Inc. J Biomed Mater Res Part A: 103A: 439-450, 2015.

Key Words: bone regeneration, subcutaneous, intramuscular, adipose tissue-derived mesenchymal stem cells, bone morphogenetic protein-2

How to cite this article: Ma J, Yang F, Both SK, Prins H-J, Helder MN, Pan J, Cui F-Z, Jansen JA, van den Beucken JJJP. 2015. Bone Forming Capacity of Cell- and Growth Factor-Based Constructs at Different Ectopic Implantation Sites. J Biomed Mater Res Part A 2015:103A:439-450.

\section{INTRODUCTION}

The worldwide incidence (i.e., 2.2 million annually ${ }^{1}$ ) of bone disorders and bone defects has increased substantially and is expected to double by $2020 .^{2}$ The potential of bone regeneration strategies becomes especially challenging under compromised conditions, such as patients with medically compromised conditions (e.g., osteoporosis, diabetes, and cancer), or in case of critical size bone defects and bone defects cannot heal spontaneously. ${ }^{2}$ The gold standard of current therapeutic strategies is autologous bone grafts. However, the limitation in bone amount to be harvested and donor site morbidity (e.g., pain and infection) are disadvantageous for the clinical use of autologous bone grafts. The use of allografts can avoid these disadvantages, but is

Correspondence to: Jeroen JJP van den Beucken; e-mail: jeroen.vandenbeucken@radboudumc.nl

Contract grant sponsor: Royal Netherlands Academy of Arts and Sciences; contract grant number: KNAW, 08-PSA-M-02

Contract grant sponsor: National 973 project of China

Contract grant sponsor: 2011CB606205 
associated with risks of disease transmission or immunogenic rejection. ${ }^{3}$ Bone tissue engineering and regenerative medicine (BTE/RM), using constructs based on combinations of scaffolds, cells, and growth factors are considered as a promising alternative approach to repair bone defects.

Bone morphogenetic protein 2 (BMP-2) is the most extensively studied osteoinductive factor ${ }^{4}$ and is currently available via recombinant technology-based production methods. Recombinant human (rh)BMP-2 has been widely used as a component in several commercially available bone regenerative products (e.g., Infuse ${ }^{\circledR}$ and Amplify ${ }^{\mathrm{TM}}$ Matrix), which have received FDA-approval for several clinical applications, such as spinal fusion, ${ }^{5}$ treatments of cleft lip and palate, ${ }^{6}$ and maxillofacial bone defects. ${ }^{7,8}$

Mesenchymal stem cells (MSCs) represent the high potential cell type for bone regeneration ${ }^{9}$ as a result of the multipotential differentiation capacity including differentiation into the osteogenic lineage. ${ }^{10}$ Despite of the exciting outcomes in animal studies, in which bone regeneration was demonstrated using human MSCs, ${ }^{11,12}$ the application of human MSCs in a clinical setting is far behind. Since mid 2012 , there is only one approved stem cell product on the market in the United States (Hemacord $₫$, i.e., hematopoietic progenitor cells from cord blood for patients with disorders affecting the hematopoietic system) and only one approved stem cell drug in Canada (Prochymal ${ }^{\text {, }}$, i.e. a stem cell therapy based on allogenic MSCs to treat acute graft-vs.-host disease). ${ }^{13}$ To date, no stem cell-based product is available for bone regeneration, although both clinical trials and few unlicensed human MSCs treatments have been carried out. ${ }^{14}$ For bone regeneration in clinical applications, beyond the safety and efficacy aspects, vascularization plays an essential role. Insufficient vascularization caused by the slow rate $(<1 \mathrm{~mm} /$ day $)$ of blood vessel infiltration into the tissue-engineered constructs hampers cell survival and successful integration of the graft. ${ }^{15}$ Coculture of MSCs with endothelial (progenitor) cells (ECs) has attracted most attention in strategies that seek rapid vascularisation. ${ }^{16}$ Surprisingly, such cocultures are demonstrated to induce higher in vitro mineralization ${ }^{17}$ and more in vivo bone formation $^{18,19}$ compared with MSCs monocultures, but no clinical data are available yet. Adipose tissue-derived MSCs (ATMSCs) were explored within the last decade ${ }^{20}$ due to the easy handling in cell harvesting and high cell yields reviewed previously. ${ }^{21,22}$ Limited data are available on cocultures using AT-MSCs in combination with ECs.

The apparent unsatisfactory bone regenerative capacity of human MSCs in clinics leads to an interest in analyzing the potential causative mechanisms. The earlier mentioned lack of vascular supply and related cell death after implantation, $^{23}$ is suggested to be a major cause of failure of BTE/ RM in patients. ${ }^{24}$ From this, it is straightforward to assume that different implantation sites, which differ in blood flow and thereby oxygen, nutrition supply, and waste products removal, ${ }^{25}$ influence the bone forming capacity of BTE/RM constructs. Experimentally, ectopic implantation models have been used tremendously for the evaluation of osteoinductive scaffolds, bone-forming stem cells, and growth fac-

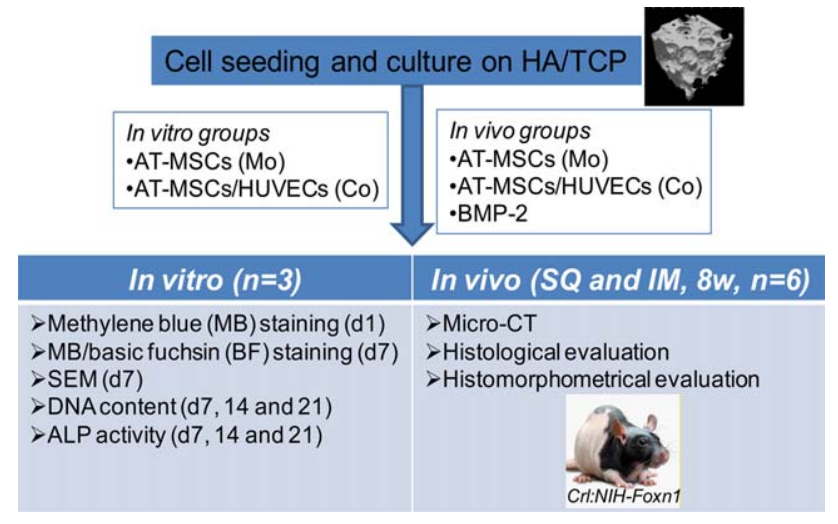

FIGURE 1. Schematic representation of the experimental design. SQ, subcutaneous; IM, intramuscular. [Color figure can be viewed in the online issue, which is available at wileyonlinelibrary.com.]

tors. Subcutaneous (SQ) and intramuscular (IM) implantation are the two mainly used ectopic models, for which vascularization (IM $>\mathrm{SQ}$ ) has been regarded as the predominant difference. $^{25}$

The aim of this study was to compare the effect of implantation site (i.e., SQ vs. IM) on the bone forming capacity of cell- and growth factor-based constructs in athymic nude rats after 8 weeks implantation. We hypothesized that IM implantation would induce higher amounts of bone formation compared with SQ implantation, irrespective of the scaffolds used, owing to an increased vascularization in muscle tissue compared with SQ connective tissue. Porous hydroxyapatite/tricalcium phosphate (HA/TCP) was used as a scaffold, with either precultured (7 days in osteogenic medium) AT-MSCs or AT-MSCs/human umbilical vein ECs (HUVECs) to generate cell-based constructs or preadsorbed BMP-2 $(20 \mu \mathrm{g} / \mathrm{scaffold})$ to generate growth factor-based constructs. Histological and histomorphometrical analysis were used to assess bone formation. A differentiation experiment was performed in parallel to compare in vitro the osteogenic capacity of cell-based constructs.

\section{MATERIALS AND METHODS}

\section{Experimental set-up}

The experimental set-up is schematically represented in Figure 1. An in vitro parallel study was used to compare the osteogenic capacity of AT-MSCs and AT-MSCs/HUVECs cultured on HA/TCP scaffolds. To further compare the bone forming capacity in the two implantation sites (SQ and IM), HA/TCP scaffolds combined with either cells (AT-MSCs or AT-MSCs/HUVECs) or growth factor (BMP-2) were implanted in athymic nude rats for 8 weeks and bone formation was assessed histologically and histomorphometrically.

\section{Cell isolation and culture}

Human subcutaneous adipose tissue from the abdomen was obtained from waste material from the Department of Plastic Surgery (Tergooi Hospital, Hilversum, the Netherlands) after written informed consent. This study complied with the principles of the Declaration of Helsinki. 
TABLE I. Cell Culture Media Used in the Study

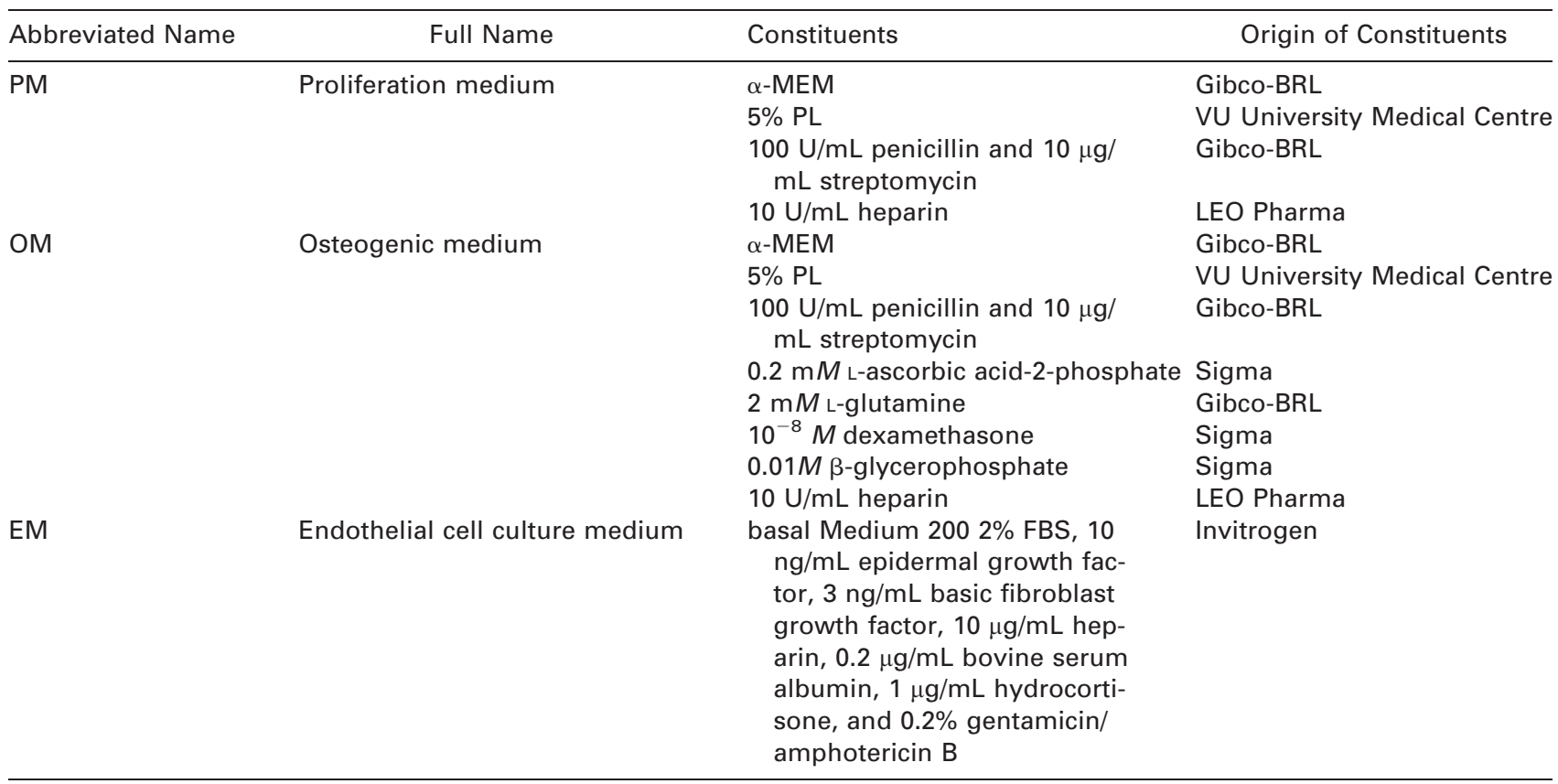

$\alpha-M E M$, minimal essential medium; PL, human platelet lysate; FBS, fetal bovine serum.

AT-MSCs isolation was performed according to a previously described protocol. ${ }^{26}$ Briefly, resected tissue was minced using surgical scalpel and scissor and digested with $0.1 \%$ collagenase A (Roche Diagnostics GmbH, Mannheim, Germany) in phosphate-buffered saline (PBS; B. Braun, Melsungen, Germany) containing $1 \%$ bovine serum albumin (BSA; Roche Diagnostics) at $37^{\circ} \mathrm{C}$ for $45 \mathrm{~min}$ with shaking. The digested tissue was centrifuged $(600 \mathrm{~g})$ for $10 \mathrm{~min}$ and the cell pellet was resuspended in $5 \mathrm{~mL}$ of PBS/1\% BSA and filtered with a $200 \mu \mathrm{m}$ mesh (Roche Diagnostics). Cells were then subjected to a Ficoll density centrifugation step to remove erythrocytes and were plated at a density of 100,000 cells $/ \mathrm{cm}^{2}$. Proliferation medium was used for cell expansion, in which human platelet lysate (PL) was supplemented (PM, see Table I) because PL-supplementation in medium has been proved to be optimal for AT-MSCs culture. ${ }^{27}$ AT-MSCs from 1 donor (female, 38 years old) from passage 4 were used in the experiment. These cells have been confirmed to mineralize in vitro according to our previous study. ${ }^{27}$

HUVECs were obtained from a commercial source (Becton Dickinson Biosciences, BD; Breda, the Netherlands) and cultured in endothelial cell culture medium (EM, see Table I) according to instructions from BD. Cells from passage 7 were used in the experiment.

\section{Scaffold preparation and cell seeding}

Porous cubic biphasic 75\% HA/ $25 \% \beta$-TCP ceramic scaffolds (Camceram ${ }^{\circledR} ; 3 \times 3 \times 3 \mathrm{~mm}^{3}$; CAM Bioceramics $\mathrm{BV}$, Leiden, the Netherlands) with a volumetric porosity of $\sim 75 \%$, and a pore diameter ranging from 100 to $500 \mu \mathrm{m}$ were used in this study. The scaffolds were sterilized by autoclaving and prewetted in 50\% fetal bovine serum (in alpha minimum essential medium) overnight before cell seeding. A total of 30 scaffolds were put into a $20-\mathrm{mL}$ syringe (BD Plastipak), in which $10 \mathrm{~mL}$ of osteogenic medium (OM, see Table I) containing a total number of 30 $\times 10^{6}$ cells (AT-MSCs or AT-MSCs/HUVECs (50:50) was included. AT-MSCs and HUVECs were seeded at a ratio of 50 : 50 (previously demonstrated optimal for osteogenesis ${ }^{28}$ ). Cells were seeded by rotating at a speed of $12 \mathrm{rpm}$ at $37^{\circ} \mathrm{C}$ in a humid atmosphere for $3 \mathrm{~h}$. Next, the cell-based scaffolds were transferred from the syringe into nonadhesive 25-well square plates (Greiner Bio-one). The unattached cells from the syringe were resuspended into OM, divided, and dripped onto each scaffold $(50 \mu \mathrm{L})$ and the scaffolds were incubated for another hour. Subsequently, $1.5 \mathrm{~mL}$ of $\mathrm{OM}$ was added to each well and the cell-based scaffolds were cultured at $37^{\circ} \mathrm{C}$ in a humid atmosphere in OM for 7 days, with medium refreshment twice. Thereafter, the cellbased scaffolds were randomly assigned to enrollment in in vitro and in vivo experiments. For in vitro experiments, scaffolds were collected on different time points (days 7, 14, and 21) for evaluation of cell morphology, proliferation and differentiation. For in vivo experiments, both cell-based and growth factor-based scaffolds were used. For preparation of growth factor-based scaffolds, $30 \mu \mathrm{L}$ of BMP-2 (InductOs ${ }^{\circledR}$, London, UK) solution (containing $20 \mu \mathrm{g}$ BMP-2 in $30 \mu \mathrm{L}$ of PBS) was dripped onto each scaffold in sterilized nonadhesive 25-well plates and allowed to adsorb for $2 \mathrm{~h}$.

\section{In vitro performance of cell-based scaffolds}

To analyze cell proliferation and osteogenic differentiation of the seeded cells, an in vitro study was performed $(n=3)$, including the following three groups:

- HA/TCP (no cells); 
- Mo (HA/TCP scaffolds seeded with AT-MSCs monoculture);

- Co (HA/TCP scaffolds seeded with AT-MSCs/HUVECs coculture).

\section{Methylene blue staining}

On day 1 , scaffolds were stained with methylene blue (MB) to observe cell distribution on the surface. The staining method used was slightly modified according to the web protocol. $^{29}$ Briefly, scaffolds were washed with PBS three times and then 1\% MB (Merck, Darmstadt, Germany) solution was added to each scaffold at room temperature for 5 min. Afterwards, the scaffolds were washed thoroughly with PBS until no residual color could be washed out. The scaffolds were maintained in PBS and imaged using a stereomicroscope (Leica MZ12, Rijswijk, the Netherlands) equipped with a Leica camera (Leica DC200, Rijswijk, the Netherlands).

\section{Methylene blue/basic fuchsin staining and scanning electron microscopy}

In order to observe cell morphology on day 7 (time point of parallel in vivo implantation), MB/basic fuchsin (BF) staining as well as scanning electron microscopy (SEM) analysis were performed. For MB/BF staining, scaffolds $(n=3)$ were washed with PBS and fixed in 10\% neutral formalin for $2 \mathrm{~h}$. After fixation, the scaffolds were dehydrated in a graded series of ethanol and embedded in methylmethacrylate. Thin sections ( $10 \mu \mathrm{m} ; 3$ per scaffold) were prepared using a histological diamond saw (Leica Microsystems SP 1600, Nussloch, Germany) and stained with $1 \% \mathrm{MB}$ and $0.3 \% \mathrm{BF}$.

For SEM analysis, scaffolds were rinsed with filtered PBS, and fixed in $2 \%$ glutaraldehyde for $2 \mathrm{~h}$. Then, the scaffolds $(n=3)$ were washed with $0.1 M$ sodium-cacodylate for $30 \mathrm{~min}$, dehydrated in a graded series of ethanol, and dried with tetramethylsilane (Merck, Frankfurt, Germany). Examinations from both peripheral and cross-sections of the scaffolds were performed using a SEM (JEOL 6340F, Peabody, USA) after deposition of a sputter-coated gold layer.

\section{DNA content and alkaline phosphatase activity}

DNA content and alkaline phosphatase (ALP)-activity (extraand intracellular ALP-activity separately) were assessed for evaluation of cell proliferation and osteogenic differentiation, respectively, at multiple time points (days 7, 14, and 21). First, medium from each scaffold (bare HA/TCP and cell-based scaffolds) was collected for extracellular ALP-activity measurements. For sampling, scaffolds $(n=3)$ were cultured in a precise volume of medium $(1.5 \mathrm{~mL})$ and collected at indicated time points during medium refreshment. The medium was stored at $-80^{\circ} \mathrm{C}$ until the measurement. After medium collection, the same scaffolds were used for sampling of DNA content and intracellular ALP-activity samples via rinsing with PBS, addition of $1 \mathrm{~mL}$ of MilliQ per scaffold, and two freezethaw cycles $\left(-80^{\circ} \mathrm{C} \sim 37^{\circ} \mathrm{C}\right)$ before biochemical analysis.

Both DNA content and ALP-activity assays were carried out according to previously described methods. ${ }^{17}$ DNA con- tent was measured using Quant-iT ${ }^{\mathrm{TM}}$ Picogreen Kit (Invitrogen; Breda, the Netherlands) and ALP-activity was determined using an ALP assay kit (p-nitrophenyl phosphate, pNPP; Sigma-Aldrich, the Netherlands). Values of the ALP-activity in cell-seeded scaffolds were corrected by subtracting the values from HA/TCP scaffolds without cells to exclude the effects of bare scaffolds.

\section{In vivo experiment design}

Nine healthy 6-weeks old male athymic nude rats (weight 150-200 g; Crl:NIH-Foxn $1^{\text {rnu}}$, Charles River) were used according to national guidelines for the use and care of laboratory animals and after ethical approval by the Animal Ethical Committee (RU-DEC 2012-013).

After in vitro pre-culture for 7 days, cell-based constructs were randomly distributed for implantation either at SQ or IM sites. Three groups were defined for each implantation site, with six scaffolds for each group $(n=6)$ :

- Mo (HA/TCP scaffold seeded with AT-MSCs monoculture);

- Co (HA/TCP scaffold seeded with AT-MSCs/HUVECs coculture);

- BMP-2 (HA/TCP scaffold loaded with BMP-2).

\section{Surgical procedure}

For surgery, the animals were premedicated by subcutaneous injection of carprofen $\left(5 \mathrm{mg} / \mathrm{kg}\right.$; Rimadyl ${ }^{\circledR}$, Pfizer Animal Health B.V., Capelle aan de IJssel, Netherlands) to reduce operative pain. Surgery was performed under general anesthesia with nitrous oxide, oxygen, and isoflurane.

For SQ implantation, the animals were immobilized and placed in a ventral position. The back of the animals was shaved and disinfected with povidone-iodine. A longitudinal incision was made on each side of the vertebral column. A subcutaneous pocket was created using blunt dissection. After placement of the scaffolds, the skin was closed using 4-0 Vicryl ${ }^{\circledR}$ resorbable sutures.

For IM implantation in the adductor thigh muscle, the animals were placed in a dorsal position. The groin and leg area were shaved, disinfected with povidone-iodine, and a longitudinal incision was made in the thigh. The incision was through the fascia and a pocket was made in the adductor thigh muscle. After the scaffolds were placed into the pockets, the soft tissues were closed in two layers with 5-0 and 4-0 Vicryl ${ }^{\circledR}$ resorbable sutures.

Each animal received four constructs in total (2 constructs for SQ implantation and 2 constructs for IM implantation, with 1 construct per pocket in each lateral side. After surgery, subcutaneous injections of carprofen $(5 \mathrm{mg} / \mathrm{kg}$; Rimadyl ${ }^{\circledR}$ ) were given for 2 days to reduce postoperative pain.

\section{Explantation and micro-computed tomography}

Eight weeks after implantation, animals were euthanised using $\mathrm{CO}_{2}$ suffocation. The specimens with the surrounding tissue were retrieved. Next, the specimens were fixed in 

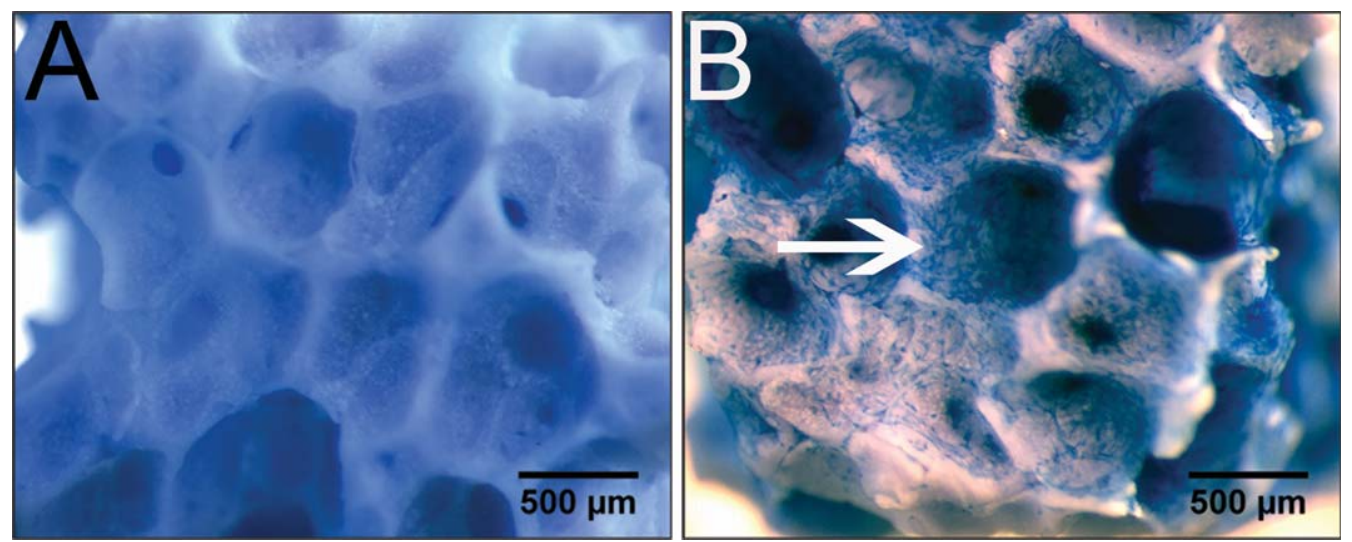

FIGURE 2. Microscopic observation using methylene blue staining on HA/TCP on day 1 in vitro $(n=3)$. (A) bare HA/TCP scaffold and (B) cellseeded scaffold (from AT-MSCs seeded HA/TCP, Mo). Arrow indicates cells. [Color figure can be viewed in the online issue, which is available at wileyonlinelibrary.com.]

$10 \%$ neutral formalin for $24 \mathrm{~h}$ and transferred into $70 \%$ ethanol for micro-computed tomography (micro-CT) scanning. Two specimens $(n=2)$ randomly selected from each group were used for micro-CT imaging. The specimens were imaged using a high resolution SkyScan-1172 micro-CT imaging system (SkyScan, Aartselaar, Belgium). Next, cone beam reconstruction was performed on the projected files using Nrecon V1.5 (SkyScan, Kontich, Belgium). Finally, a 3D-reconstruction of the specimens was obtained by using 3D creator software as previously described. ${ }^{30}$ The porosity of each specimen was analyzed using Bruker-CT-Analyser software (Coventry, UK). In brief, a volume of interest (VOI) with a cubic volume of interest of $8 \mathrm{~mm}^{3}$ was selected from the center of each specimen from the 3D-reconstructed image. A threshold (61 for $x$-axis and 255 for $y$-axis, represent gray value of scaffold and mineralized tissue and its density, respectively) of gray values was selected and the values above and below this value were regarded separately as: material and mineralized tissue; void and soft tissue. It is not possible to distinguish mineralized tissue/bone from the HA/TCP material. The pore volume was determined by subtracting the volume of the former part (i.e., material and mineralized tissue) from the total VOI. Thereafter, the porosity volume percentage for each specimen was calculated by dividing the porosity volume $\left(\mathrm{mm}^{3}\right)$ by the total VOI $\left(\mathrm{mm}^{3}\right)$.

\section{Histological and histomorphometrical evaluation}

After fixation, the specimens were dehydrated in a graded series of ethanol and embedded in methylmethacrylate. Thin sections ( $10 \mu \mathrm{m}$; 3 per specimen) were prepared using a histological diamond saw (Leica) and stained with MB/BF.

All histological sections were photographed with the Zeiss Imager Z1 microscope equipped with the AxioCam MRc5 camera using AxioVision 4.8 software (Carl Zeiss Microimaging $\mathrm{GmbH}$, Göttingen, Germany). By using the Mosaic function of AxioVision 4.8 software, high resolution images of each full sized section could be obtained. Three sections were made per specimen and these 3 sections per specimen were analyzed. The incidence of bone formation for each group was analyzed. Furthermore, histomorphometrical evaluation was performed to quantify bone formation within the three experimental groups (Mo, Co, and BMP-2) in both SQ and IM sites according as described previously. ${ }^{31}$ In brief, histological sections were scored using computer-based image analysis techniques (Leica ${ }^{\circledR}$ Qwin Proimage analysis system, Wetzlar, Germany), which recognize bone tissue from the others (e.g., HA/TCP scaffolds, pores and soft tissues) based on different RGB values from magnified digitalized images $(100 \times)$. Manual corrections based on morphological appearance were applied to ensure adequate selection of newly formed bone tissue within the selected area. A region of interest (ROI) was defined by selecting the area within fibrous tissue capsule. The parameters for evaluating bone amount as listed below were measured:

- BA/PA (\%): bone area $\left(\mathrm{mm}^{2}\right) /$ pore area $\left(\mathrm{mm}^{2}\right)$;

- BA/ROI (\%): bone area $\left(\mathrm{mm}^{2}\right) /$ region of interest $\left(\mathrm{mm}^{2}\right.$, i.e., the scaffold area).

\section{Statistical analysis}

Data were expressed as mean \pm standard deviation. Graphpad Instat software (Instat ${ }^{\circledR} 3.05$, Graphpad Software, La Jolla, USA) was used for statistical analysis. For the statistical analysis for DNA content and ALP-activity in vitro $(n=3)$, an independent $t$-test was performed to compare between Mo and Co and a one-way ANOVA with posthoc Tukey HSD test was applied for the comparison among different time points (days 7, 14, and 21). For the comparison of bone formation in SQ and IM sites in vivo $(n=6)$, a paired $t$-test was performed. $p<0.05$ was defined as statistically significant.

\section{RESULTS}

Microscopic observation for cell-based scaffolds in vitro MB staining (Fig. 2) on day 1 showed an apparent difference between bare HA/TCP scaffolds [Fig. 2(A)] and the 

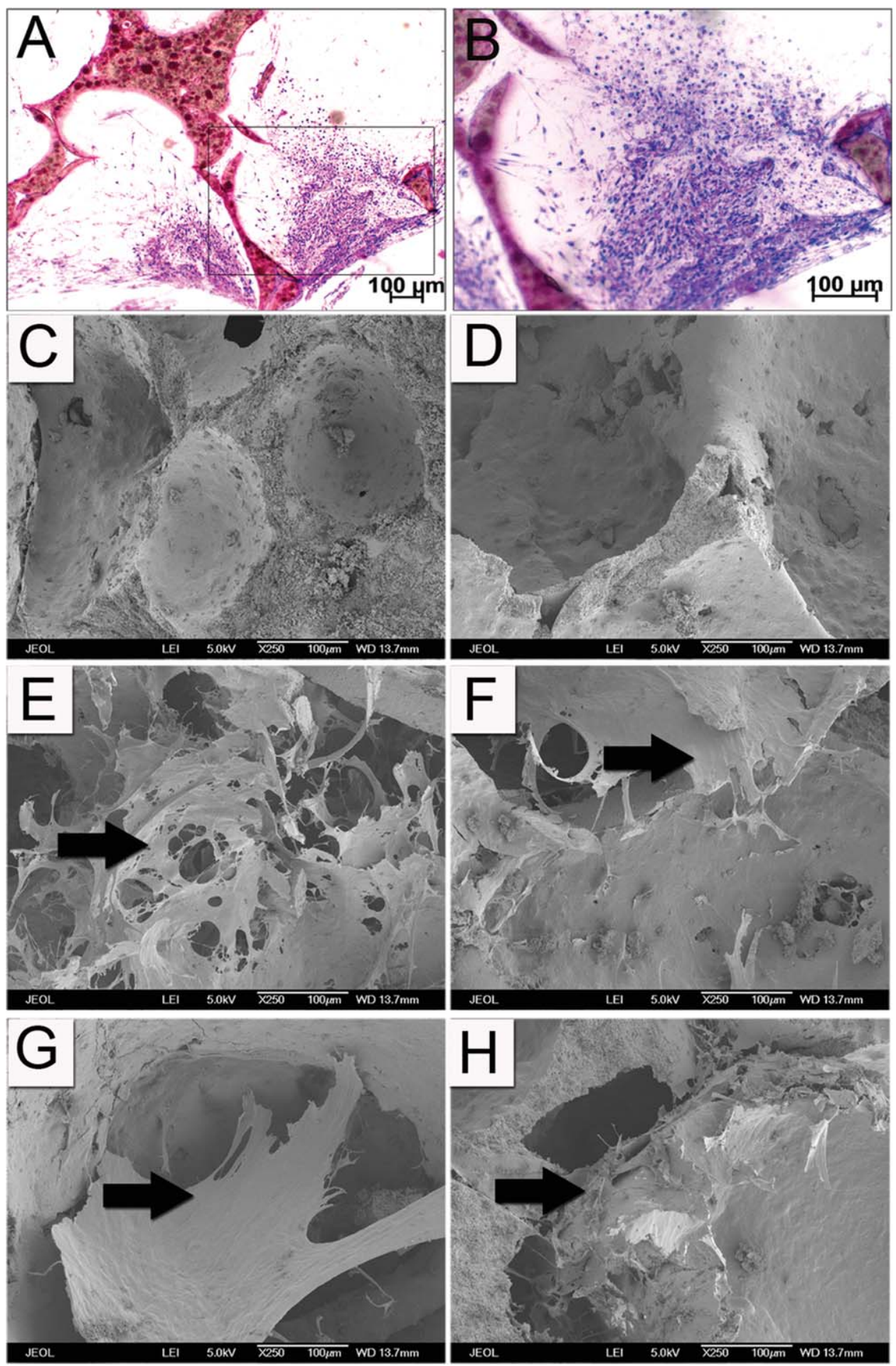

FIGURE 3. Microscopic observation of cell morphology on HA/TCP on day 7 in vitro $(n=3)$. A: representative image of methylene blue/basic fuchsin staining for cell-seeded scaffolds (from AT-MSCs/HUVECs seeded HA/TCP, Co). B: Magnified image of the insert in (A). C-H: Represent scanning electron microscopy images of both peripheral $(C, E, G)$ and cross-sections $(D, F, H)$ for bare HA/TCP, Mo, and Co, respectively. Arrows indicate cell layer. [Color figure can be viewed in the online issue, which is available at wileyonlinelibrary.com.]

cell-based constructs [Fig. 2(B), representative image from Mo], for which the latter clearly demonstrated positively stained cell nuclei. The same trend was observed for Mo and Co, for which a representative image from Mo is shown.
On day 7, microscopic observation including both $\mathrm{MB} / \mathrm{BF}$ staining and SEM was performed to observe the cell morphology for the cell-based constructs. MB/BF staining showed that cells penetrated inside the pores [Fig. 3(A)], 

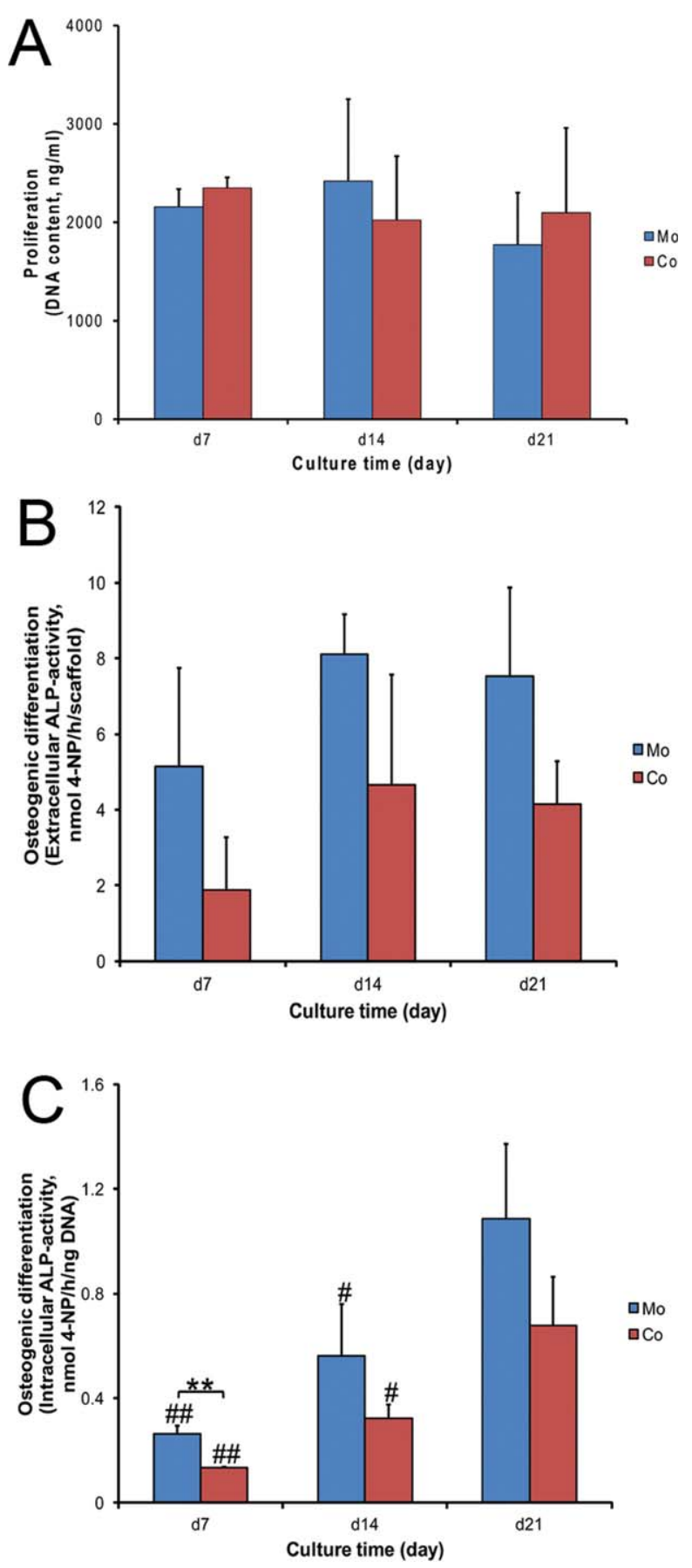

FIGURE 4. Cell proliferation and osteogenic differentiation on HA/TCP in vitro $(n=3)$. (A) DNA content; (B) extracellular ALP-activity (from cell culture medium); (C) intracellular ALP-activity (from cell lysis). ${ }^{*} p<0.01$, indicates significant difference between Mo and Co; $\# p<0.05 ; \# \#<0.01$, indicate significant difference on day 7 vs. day 21 or day 14 vs. day 21. Mo, AT-MSCs seeded HA/TCP; Co, AT-MSCs/ HUVECs seeded HA/TCP. [Color figure can be viewed in the online issue, which is available at wileyonlinelibrary.com.]

and at higher magnification, cell nuclei were clearly observed [Fig. 3(B)]. The structure of the bare HA/TCP scaffolds was shown from both peripheral [Fig. 3(C)] and crosssections [Fig. 3(D)] using SEM analysis. SEM images demonstrated cell distribution on the surface [Fig. 3(E,G)] as well as cell ingrowth into the centre of the constructs [Fig. $3(\mathrm{~F}, \mathrm{H})$ ] for both Mo [Fig. 3(E,F)] and Co [Fig. 3(G,H)]. Cells clearly covered the surface of the constructs, whereas crosssections displayed the presence of cells throughout the porous structure of the constructs.

\section{In vitro performance of cell-based scaffolds}

DNA content, as an index for cell proliferation, is displayed in Figure 4(A). No significant difference was observed between Mo and Co at any time point. Additionally, Mo and Co constructs showed a rather constant DNA content over time.

Both the extra- and intracellular ALP-activity were analyzed and the results are shown in Figure 4(B,C). For extracellular ALP-activity [Fig. 4(B)], no significant differences were found between Mo and Co at individual time points or over time $(p>0.05)$, although a tendency toward higher ALP-activity for Mo constructs was apparent. For intracellular ALP-activity [Fig. 4(C)], significantly higher values were found for Mo constructs compared with Co constructs on day $7(p<0.01)$, while similar values were observed for Mo and Co on days 14 and 21. Analogous to extracellular ALPactivity results, intracellular ALP-activity showed a tendency toward higher ALP-activity for Mo constructs. Comparison among different time points demonstrated that intracellular ALP-activity increased over time for both Mo and Co constructs, showing significantly higher values on day 21 than on day 7 and day 14 .

\section{In vivo experiment}

General observations. All animals recovered uneventfully from the surgery and no infections or complications were observed during the 8 week implantation period. All specimens ( $n=6$ per group) were retrieved and during retrieval, no macroscopic signs of inflammation or adverse tissue response were observed at the implantation sites. Obvious soft tissue encapsulation was observed for all constructs at all implantation sites.

Micro-computed tomography. A 3D reconstruction was generated using micro-CT and the porosity of the constructs was determined [Fig. 5]. The 3D reconstructions showed porous structures of the constructs, with large similarity for constructs from both implantation sites. The dimension and the number of the pores showed an apparent decrease for growth factor-based constructs compared with both original bare scaffolds and cell-based constructs. The porosity of the bare scaffolds $(n=2)$ was $67.0 \pm 11.0 \%$. The average values of porosity for the two randomly selected specimens in each group showed a decrease in the BMP-2 group $(33.4 \pm 3.9 \%$ in SQ and $37.4 \pm 3.4 \%$ in IM) compared with Mo $(49.0 \pm 19.0 \%$ in SQ and $56.5 \pm 26.1 \%$ in IM) and Co constructs $(58.2 \pm 0.1 \%$ in SQ and $66.5 \pm 6.6 \%$ in IM), which showed a comparable porosity.

Descriptive histology. Histological images for sections of SQ and IM implantation are presented in Figures 6 and 7, respectively. Similar results were observed for SQ and IM implantation sites. In general, none of the specimens 


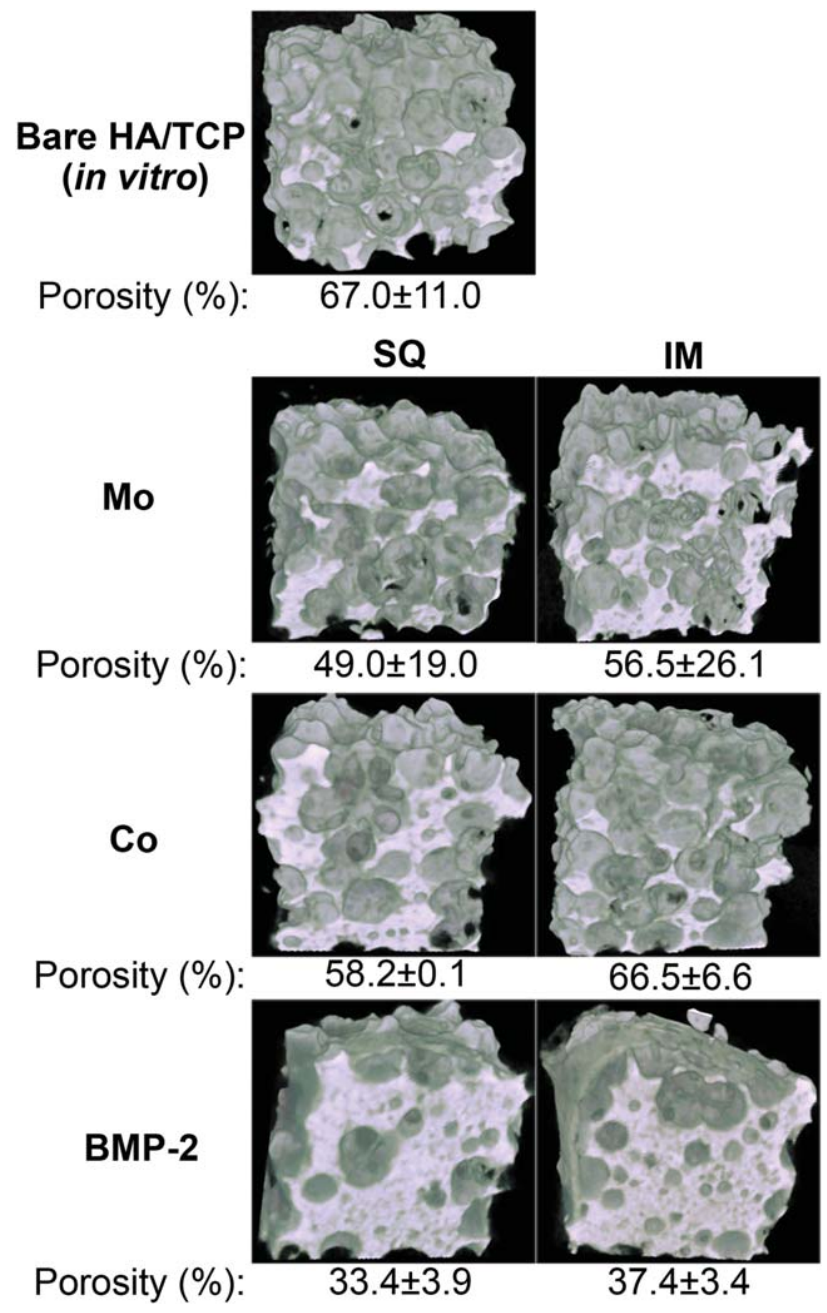

FIGURE 5. Micro-CT 3D reconstructions for Mo, Co, and BMP-2 scaffolds after 8 weeks in vivo implantation $(n=2)$. Mo, AT-MSCs seeded HA/TCP; Co, AT-MSCs/HUVECs seeded HA/TCP; BMP-2, BMP-2 loaded HA/TCP; SQ, subcutaneous; IM, intramuscular. [Color figure can be viewed in the online issue, which is available at wileyonlinelibrary. com.]

showed the presence of an inflammatory response and soft tissues (i.e., layers of fibrous cells) firmly encapsulated the implanted scaffolds. For Mo and Co constructs, the porous structure of the scaffolds was filled with fibrous tissues. In contrast, growth factor-based constructs showed large amounts of bone tissue present, predominantly at the concave areas of the pores. Moreover, bone formation was observed both on the periphery and in the centre of the constructs and bone marrow-like tissue was observed inside the pores of the scaffold. At higher magnification [Figs. 6 and 7], osteocyte-like cells were clearly visible within the newly formed bone tissue. Additionally, vessel-like structures, with different shape and size, were frequently observed for all the groups. However, blood cells were seldom found which might be due to the saw procedure.

Bone forming incidence. Bone formation was observed in none of the specimens $(0 / 6)$ for both Mo and Co constructs, while all of the specimens (6/6) of the growth factor-based constructs showed the presence of bone tissue, irrespective of implantation site.

Histomorphometry. Histomorphometrical evaluation of bone formation for growth factor-based constructs at both SQ and IM sites was performed, for which the results are displayed in Figure 8. The percentage of BA/PA at SQ and IM sites was similar ( $35 \pm 8 \%$ and $33 \pm 4 \%$, respectively). Similarly, the percentage of BA/ROI at SQ and IM sites was comparable ( $20 \pm 5 \%$ and $19 \pm 3 \%$, respectively).

\section{DISCUSSION}

The aim of this study was to compare the effect of implantation site on the bone forming capacity of cell-based or growth factor-based constructs in athymic nude rats after an implantation period of 8 weeks. It was hypothesized that IM implantation would induce more bone formation in comparison to SQ implantation due to more pronounced vascularization in IM site. Porous HA/TCP scaffolds were either seeded with AT-MSC monocultures or AT-MSC/HUVEC cocultures and precultured in vitro for 7 days or preloaded with BMP-2, after which the constructs were implanted. Histological and histomorphometrical analyses were used to assess bone formation. An in vitro parallel experiment was

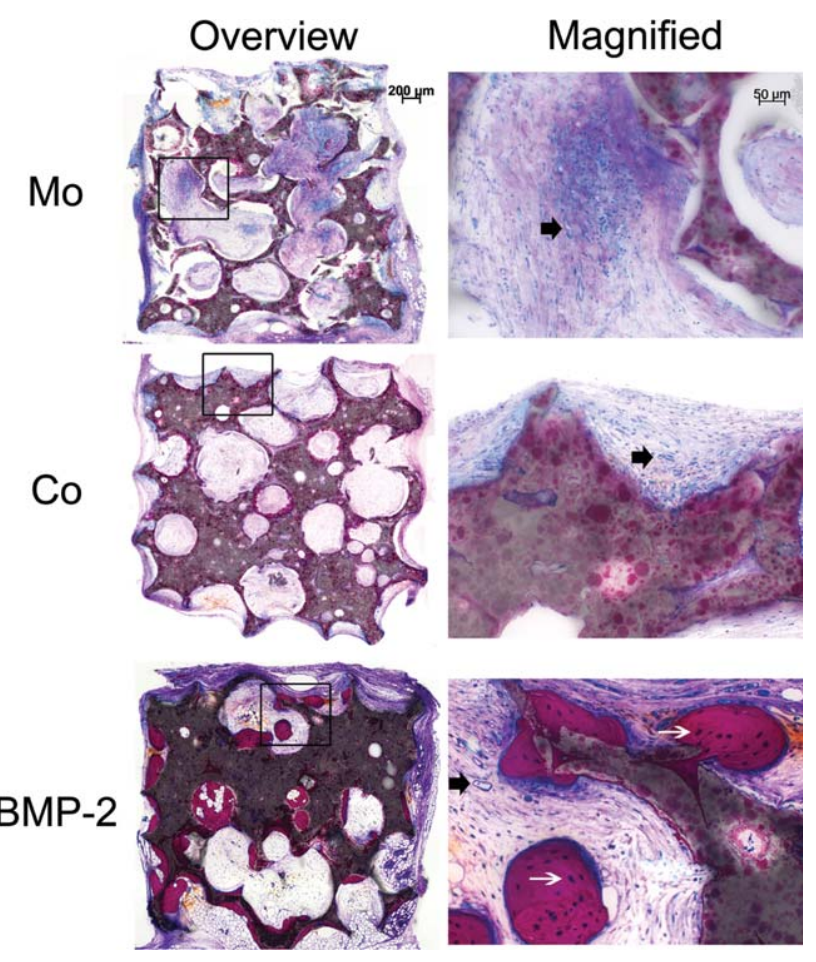

FIGURE 6. Histological images from methylene blue/basic fuchsin stained sections after 8 weeks subcutaneous (SQ) implantation in vivo $(n=6)$. Bone marrow structures are only observed in the BMP-2 group, which is also the only group with bone formation. Black arrows indicate vessel-like structures and white arrows indicate osteocyte-like cells. Mo, AT-MSCs seeded HA/TCP; Co, AT-MSCs/HUVECs seeded HA/TCP; BMP-2, BMP-2 loaded HA/TCP. [Color figure can be viewed in the online issue, which is available at wileyonlinelibrary.com.] 


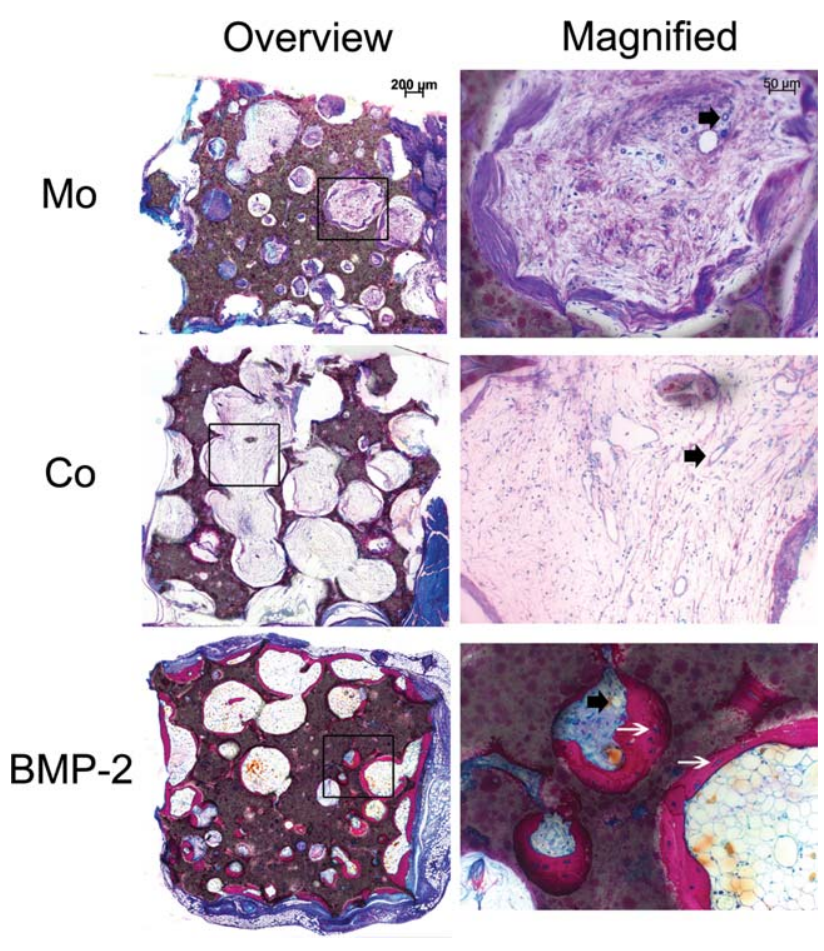

FIGURE 7. Histological images from methylene blue/basic fuchsin staining after 8 weeks intramuscular (IM) implantation in vivo $(n=6)$. Bone marrow structures are only observed in the BMP-2 group, which is also the only group with bone formation. Black arrows indicate vessel-like structures and white arrows indicate osteocyte-like cells. Mo, AT-MSCs seeded HA/TCP; Co, AT-MSCs/HUVECs seeded HA/TCP; BMP-2, BMP-2 loaded HA/TCP. [Color figure can be viewed in the online issue, which is available at wileyonlinelibrary.com.]

performed to comparatively evaluate the proliferation and osteogenic differentiation capacity of cell-based constructs. In general, cells from in vitro cultures showed osteogenic differentiation with a slightly increased ALP-activity for monocultures compared with cocultures. In vivo experiments demonstrated that only growth factor-based constructs induced bone formation without significant implantation site dependent differences in the amount of formed bone.

So far, MSCs derived from either mouse ${ }^{32}$ or rat $^{33,34}$ have been combined with various scaffolds and no difference in bone formation was observed in SQ and IM sites. Nevertheless, research is missing on such comparison using human MSCs, which behave differently with those from other animal species. ${ }^{35}$ Besides, growth factor-based (i.e., BMP-2) bone formation in SQ and IM sites was compared as well since BMP-2 induce bone formation through the recruitment and stimulation of stem cells (either from donor or host) to differentiate into osteoblasts, ${ }^{36,37}$ for which vascularization also acts as a key factor for cell survival. Moreover, although HA/TCP favors MSCs differentiation into osteogenic lineages, ${ }^{38}$ it has been reported previously that bare HA/TCP scaffolds fail in inducing bone formation in both SQ and IM implantation in rats. ${ }^{39}$ Therefore, the bare scaffold group was not included in this experimental design.
Yet, bone formation was observed in growth factorrather than cell-based constructs. In theory, BMP-2 induces osteogenic differentiation of resident stem cells and hence bone formation, but AT-MSCs (either mono- or cocultures) are expected to improve bone formation, based on their osteogenic differentiation capacities in vivo. No BMP-2 induced bone formation by resident stem cells is to be expected for cell-based constructs since either osteogenically induced AT-MSCs do not produce BMP- $2^{40}$ or the osteogenic fate of AT-MSCs is not influenced by BMP-2 both in vitro and in vivo. ${ }^{41,42}$ However, bone formation using human bone marrow MSCs (BM-MSCs) is more frequently observed because osteogenically differentiated BM-MSCs can secrete much higher amount of BMP-2 compared with ATMSCs. ${ }^{40}$

Our study further showed that IM implantation did not enhance bone formation compared with SQ implantation for growth factor-based scaffolds. The hypothesis that IM implantation can induce more bone formation was based on the fact that more pronounced vascularization in IM tissue ${ }^{43,44}$ can provide more oxygen and nutrition supply for osteoblastic cells as well as recruitment of more stem cells from the circulation, and hence enhance bone formation. ${ }^{45}$ Up to now, bone forming capacity of only rat BM-MSCs seeded constructs was compared in SQ and IM implantation, and equal bone formation was observed. ${ }^{33,34}$ Nevertheless, it is still unclear for the bone formation in SQ vs. IM when human AT-MSCs are used since no bone formation was observed in either of the implantation sites. Moreover, our study showed that BMP-2 induced similar bone formation at the two different ectopic implantation sites. This is inconsistent with the previous reports which showed that $5 \mu \mathrm{g}$ BMP-2 induced more bone formation in IM compared with SQ implantation site using collagen gels as a carrier. ${ }^{46,47}$ Although only one dose of BMP-2 (i.e., $20 \mu \mathrm{g} /$ construct) was

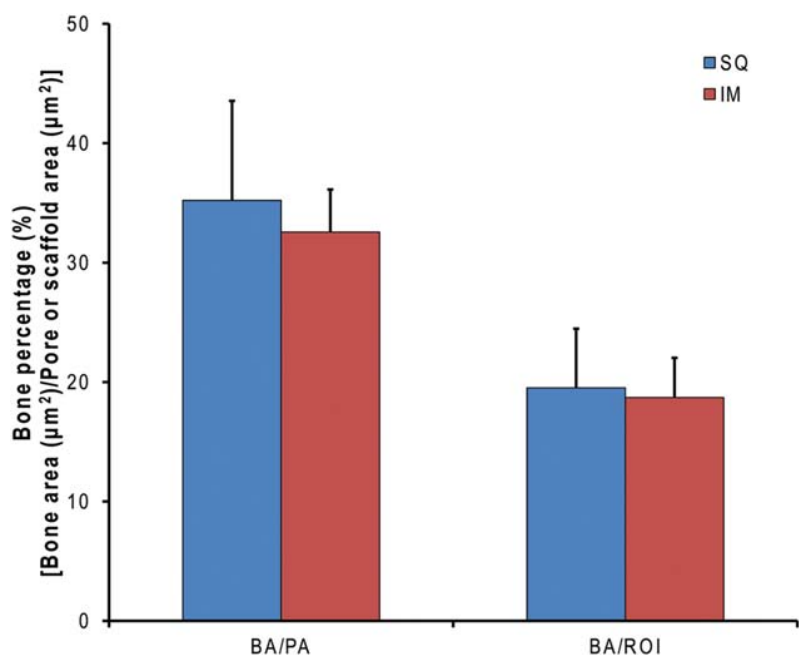

FIGURE 8. Histomorphometrical analysis of bone formation in BMP-2 scaffolds after 8 weeks in vivo implantation $(n=6)$. SQ, subcutaneous; $\mathrm{IM}$, intramuscular; $\mathrm{BA}$, bone area; PA, pore area; ROI, region of interest. [Color figure can be viewed in the online issue, which is available at wileyonlinelibrary.com.] 
used in this study, it cannot be excluded that different dosages of BMP-2 may influence bone formation of the two implantation sites.

Strong arguments exist for the in vivo bone forming capacity of AT-MSCs, even though their in vitro osteogenic differentiation capacity has been well established. ${ }^{40,48,49}$ Using human AT-MSCs, few studies have demonstrated (effects on) in vivo bone formation, either ectopically ${ }^{49}$ or orthotopically, ${ }^{51,52}$ while others found no bone formation ectopically $^{53,54}$ or orthotopically. ${ }^{28}$ But it is hard to tell the contribution of the implanted cells to bone formation, especially at orthotopic implantation sites because the origin of the formed bone was not identified. In terms of the failure in ectopic bone formation using human AT-MSCs, this study is in accordance with the research from Martin's group, ${ }^{53,54}$ in which the tissue-engineered constructs were SQ implanted for a period of 8 weeks. In one of these two studies, human AT-MSCs were statically seeded on HA ceramic scaffolds and implanted in athymic nude mice, without in vitro preculture in OM. ${ }^{54}$ In the other, human AT-MSCs were dynamically (perfusion) seeded and cultured on HA in OM for 5 days in vitro and subsequently implanted in athymic nude rats. ${ }^{53}$ These authors emphasized in a review paper that two parameters were critically required for induction of osteogenic potential by AT-MSCs, which are the osteogenic commitment of AT-MSCs and the presence of a mineral component in the scaffold. ${ }^{49}$ Although our experimental design met these two requirements, no bone formation was found. This suggests that more or other requirements are needed to obtain in vivo bone formation at ectopic implantation sites. Although considerably small scaffolds $(3 \times 3 \times 3$ $\mathrm{mm}^{3}$ ) were used, in which vascularization throughout the scaffolds might be faster in comparison to big scaffolds, no bone formation was observed in cell-based scaffolds. Nevertheless, it is not possible to dispose the potential for stem cells by ignoring the carrier selected, indicating perhaps the performance of the cells compared with the growth factor suffers from an inherent prejudice in choice of a scaffold. In this experiment, one type of calcium-phosphate based scaffold (75\% HA/25\% $\beta$-TCP) was chosen. Recent studies have shown that the bone formation capacity of MSCs is strongly affected by the calcium-content and formulation of scaffolds. ${ }^{55}$ Additionally, although no statistical analysis was performed, the porosity from micro-CT analysis demonstrated a decrease for both Mo and Co constructs after 8 weeks in vivo implantation compared with the original bare HA/TCP scaffolds, suggesting the formation of radiopaque tissue in cell-based constructs. Moreover, it has been reported that HUVECs alone cultured on TCP scaffolds induced an equal amount of bone formation as that of the bare TCP scaffolds group, meaning that HUVECs alone have limited contribution to osteogenesis ${ }^{19}$ and therefore this group was not included in our study.

The lack of bone formation in both culture conditions (Mo and $\mathrm{Co}$ ) is in contrast with cocultures using BM-MSCs, in which half of the MSCs in cocultures form even more bone compared with monocultures. ${ }^{18}$ Consistently, the in vitro results also showed the same trend, since ALP-activity was not enhanced in Co compared to Mo. Despite the observation of vessel-like structures for both Mo and Co, the technical challenge to histologically process ceramiccontaining constructs via proper (e.g., paraffin) embedding which is necessary for immunohistochemical staining, makes it hard to do quantitative analysis of blood vessel formation and determine the origin (either donor or host).

Although the hypothesis that IM implantation induces more bone formation compared with SQ implantation was not proved in this study, in both cell-based scaffolds because of the lack of bone formation and growth factorbased scaffolds due to the possible dosage effects of BMP-2, this study gives a hint that more parameters (e.g., growth factor dosage, scaffold and cell type, cell seeding density) may influence the results and thus need to be considered for such comparison. The clinical relevance of this work points toward the need for more studies (e.g., the underlying mechanisms and requirements of bone formation) to justify clinical application of AT-MSCs and AT-MSCs/HUVECs in the field of bone regenerative medicine.

\section{CONCLUSIONS}

The results of this study demonstrated that different ectopic implantation sites did not affect the bone forming capacity of either cell- or growth factor-based HA/TCP constructs. Further, bone formation was only observed for growth factor-based constructs. This study indicates that osteogenic differentiation capacity of AT-MSCs in vitro does not warrant in vivo bone formation, necessitating further research on the activation of cell-based bone formation for cytotherapeutic treatments.

\section{ACKNOWLEDGMENTS}

The authors appreciate the kind supply of HA/TCP scaffolds by CAM Bioceramics (Leiden, the Netherlands). The authors would like to thank Mr. Vincent Cuijpers for his kind assistance in micro-CT 3D image reconstructions. SEM examination was performed in collaboration with the Microscopic Imaging Centre of the Nijmegen Centre for Molecular Life Sciences (Nijmegen, the Netherlands).

\section{REFERENCES}

1. Lewandrowski KU, Gresser JD, Wise DL, Trantol DJ. Bioresorbable bone graft substitutes of different osteoconductivities: A histologic evaluation of osteointegration of poly(propylene glycol-cofumaric acid)-based cement implants in rats. Biomaterials 2000; 21:757-764.

2. Amini AR, Laurencin $C T$, Nukavarapu SP. Bone tissue engineering: Recent advances and challenges. Crit Rev Biomed Eng 2012; 40:363-408.

3. Janicki $P$, Schmidmaier G. What should be the characteristics of the ideal bone graft substitute? Combining scaffolds with growth factors and/or stem cells. Injury 2011;42 (Suppl 2):S77-S81.

4. Razzouk S, Sarkis R. BMP-2: Biological challenges to its clinical use. NY State Dent J 2012;78:37-39.

5. McKay B, Sandhu HS. Use of recombinant human bone morphogenetic protein-2 in spinal fusion applications. Spine (Phila $\mathrm{Pa}$ 1976) 2002;27(Suppl 1):S66-S85.

6. Alonso N, Tanikawa DY, Freitas Rda S, Canan L Jr, Ozawa TO, Rocha DL. Evaluation of maxillary alveolar reconstruction using a resorbable collagen sponge with recombinant human bone 
morphogenetic protein-2 in cleft lip and palate patients. Tissue Eng Part C Methods 2010;16:1183-1189.

7. Herford AS, Boyne PJ, Williams RP. Clinical applications of rhBMP-2 in maxillofacial surgery. J Calif Dent Assoc 2007;35:335341.

8. Misch CM. Bone augmentation of the atrophic posterior mandible for dental implants using rhBMP-2 and titanium mesh: Clinical technique and early results. Int $\mathrm{J}$ Periodontics Restorative Dent 2011;31:581-589.

9. Zomorodian E, Baghaban Eslaminejad M. Mesenchymal stem cells as a potent cell source for bone regeneration. Stem Cells Int 2012;2012:980353.

10. Jiang $Y$, Jahagirdar $B N$, Reinhardt $R L$, Schwartz $R E$, Keene $C D$, Ortiz-Gonzalez XR, Reyes M, Lenvik T, Lund T, Blackstad M, Du J Aldrich S, Lisberg A, Low WC, Largaespada DA, Verfaillie CM. Pluripotency of mesenchymal stem cells derived from adult marrow. Nature 2002;418:41-49.

11. Matsushima A, Kotobuki N, Tadokoro M, Kawate K, Yajima $H$, Takakura $\mathrm{Y}$, Ohgushi $\mathrm{H}$. In vivo osteogenic capability of human mesenchymal cells cultured on hydroxyapatite and on betatricalcium phosphate. Artif Organs 2009;33:474-481.

12. Ben-David D, Kizhner T, Livne E, Srouji S. A tissue-like construct of human bone marrow MSCs composite scaffold support in vivo ectopic bone formation. J Tissue Eng Regen Med 2010;4:30-37.

13. Available at: http://www.ask-cato.com/2012/05/stem-cells-whichway-to-the-clinic/ [21-05-2012].

14. Cyranoski D. Stem cells boom in vet clinics. Nature 2013;496:148149.

15. Santos MI, Reis RL. Vascularization in bone tissue engineering: Physiology, current strategies, major hurdles and future challenges. Macromol Biosci 2010;10:12-27.

16. Santos MI, Unger RE, Sousa RA, Reis RL, Kirkpatrick CJ. Crosstalk between osteoblasts and endothelial cells co-cultured on a polycaprolactone-starch scaffold and the in vitro development of vascularization. Biomaterials 2009;30:4407-4415.

17. Ma J, van den Beucken JJ, Yang F, Both SK, Cui FZ, Pan J Jansen JA. Coculture of osteoblasts and endothelial cells: Optimization of culture medium and cell ratio. Tissue Eng Part C Methods 2010;17:349-357.

18. Kaigler D, Krebsbach PH, West ER, Horger K, Huang YC, Mooney DJ. Endothelial cell modulation of bone marrow stromal cell osteogenic potential. FASEB J 2005;19:665-667.

19. Kim JY, Jin GZ, Park IS, Kim JN, Chun SY, Park EK, Kim SY, Yoo $\mathrm{J}$, Kim SH, Rhie JW, Cho DW. Evaluation of solid free-form fabrication-based scaffolds seeded with osteoblasts and human umbilical vein endothelial cells for use in vivo osteogenesis. Tissue Eng Part A 2010;16:2229-2236.

20. Tobita M, Orbay $\mathrm{H}$, Mizuno $\mathrm{H}$. Adipose-derived stem cells: Current findings and future perspectives. Dis Med 2011;11:160-170.

21. Jurgens WJ, van Dijk A, Doulabi BZ, Niessen FB, Ritt MJ, van Milligen FJ, Helder MN. Freshly isolated stromal cells from the infrapatellar fat pad are suitable for a one-step surgical procedure to regenerate cartilage tissue. Cytotherapy 2009;11:1052-1064.

22. Lindroos B, Suuronen R, Miettinen S. The potential of adipose stem cells in regenerative medicine. Stem Cell Rev 2011;7:269291.

23. James J, Steijn-Myagkaya GL. Death of osteocytes. Electron microscopy after in vitro ischaemia. J Bone Joint Surg $\mathrm{Br} 1986$ 68:620-624

24. Meijer G, de Bruijn J, Koole R, van Blitterswijk C. Cell based bone tissue engineering. PLoS Med 2007;4:e9.

25. Scott MA, Levi B, Askarinam A, Nguyen A, Rackohn T, Ting $K$ Soo C, James AW. Brief review of models of ectopic bone formation. Stem Cells Dev 2012;21:655-667.

26. Naaijkens BA, Niessen HW, Prins HJ, Krijnen PA, Kokhuis TJ, de Jong $N$, van Hinsbergh VW, Kamp O, Helder MN, Musters RJ, van Dijk A, Juffermans LJ. Human platelet lysate as a fetal bovine serum substitute improves human adipose-derived stromal cell culture for future cardiac repair applications. Cell Tissue Res 2012;348:119-130.

27. Ma J, van den Beucken JJ, Both SK, Prins HJ, Helder MN, Yang $F$, Jansen JA. Osteogenic capacity of human BM-MSCs, AT-MSCs and their co-cultures using HUVECs in FBS and PL supplemented media. J Tissue Eng Regen Med 2013. doi: 10.1002/term.1704. [Epub ahead of print].

28. Ma J, Both SK, Ji W, Yang F, Prins HJ, Helder MN, Pan J, Cui FZ Jansen JA, van den Beucken JJ. Adipose tissue-derived MSCs as monocultures or cocultures with human umbilical vein endothelial cells: Performance in vitro and in rat cranial defects. J Biomed Mater Res A 2013. doi: 10.1002/jbm.a.34775. [Epub ahead of print].

29. http://stanxterm.aecom.yu.edu/wiki/index.php?page=Methylene blue_staining [20-07-2004].

30. Schouten C, Meijer GJ, van den Beucken JJ, Spauwen $\mathrm{PH}$ Jansen JA. The quantitative assessment of peri-implant bone responses using histomorphometry and micro-computed tomography. Biomaterials 2009;30:4539-4549.

31. Ji W, Yang F, Ma J, Bouma MJ, Boerman OC, Chen Z, van den Beucken JJ, Jansen JA. Incorporation of stromal cell-derived factor-1alpha in PCL/gelatin electrospun membranes for guided bone regeneration. Biomaterials 2012.

32. Trojani C, Boukhechba F, Scimeca JC, Vandenbos F, Michiels JF, Daculsi G, Boileau P, Weiss P, Carle GF, Rochet N. Ectopic bone formation using an injectable biphasic calcium phosphate/SiHPMC hydrogel composite loaded with undifferentiated bone marrow stromal cells. Biomaterials 2006;27:3256-3264.

33. Hartman EH, Vehof JW, de Ruijter JE, Spauwen PH, Jansen JA. Ectopic bone formation in rats: The importance of vascularity of the acceptor site. Biomaterials 2004;25:5831-5837.

34. van Gaalen SM, Dhert WJ, van den Muysenberg A, Oner FC, van Blitterswijk $C$, verbout AJ, de Bruijn JD. Bone tissue engineering for spine fusion: An experimental study on ectopic and orthotopic implants in rats. Tissue Eng 2004:10(1-2):231-239.

35. Huang YZ, Cai JQ, Lv FJ, Xie HL, Yang ZM, Huang YC, Deng L. Species variation in the spontaneous calcification of bone marrow-derived mesenchymal stem cells. Cytotherapy 2013;15: 323-329.

36. Khaled EG, Saleh M, Hindocha S, Griffin M, Khan WS. Tissue engineering for bone production-stem cells, gene therapy and scaffolds. Open Orthop J 2011;5:289-295.

37. Zimmermann G, Wagner C, Schmeckenbecher K, Wentzensen A, Moghaddam A. Treatment of tibial shaft non-unions: bone morphogenetic proteins versus autologous bone graft. Injury 2009;40: S50-S53.

38. Siggers K, Frei H, Fernlund G, Rossi F. Effect of bone graft substitute on marrow stromal cell proliferation and differentiation. J Biomed Mater Res A 2010;94:877-885.

39. Yang Z, Yuan H, Tong W, Zou P, Chen W, Zhang X. Osteogenesis in extraskeletally implanted porous calcium phosphate ceramics: Variability among different kinds of animals. Biomaterials 1996; 17:2131-2137.

40. Shafiee A, Seyedjafari E, Soleimani M, Ahmadbeigi N, Dinarvand $\mathrm{P}$, Ghaemi N. A comparison between osteogenic differentiation of human unrestricted somatic stem cells and mesenchymal stem cells from bone marrow and adipose tissue. Biotechnol Lett 2011; 33:1257-1264.

41. Chou YF, Zuk PA, Chang TL, Benhaim P, Wu BM. Adipose-derived stem cells and BMP2, part 1. BMP2-treated adipose-derived stem cells do not improve repair of segmental femoral defects. Connect Tissue Res 2011;52:109-118.

42. Zuk P, Chou YF, Mussano F, Benhaim P, Wu BM. Adipose-derived stem cells and BMP2, part 2. BMP2 may not influence the osteogenic fate of human adipose-derived stem cells. Connect Tissue Res 2011;52:119-132.

43. Habibovic $P$, Sees TM, van den Doel MA, van Blitterswijk CA, de Groot K. Osteoinduction by biomaterials-physicochemical and structural influences. J Biomed Mater Res A 2006;77:747-762.

44. Gosain A, Chang N, Mathes S, Hunt TK, Vasconez L. A study of the relationship between blood flow and bacterial inoculation in musculocutaneous and fasciocutaneous flaps. Plast Reconstr Surg 1990;86:1152-1162; discussion 1163.

45. Hall BK. Hypoxia and differentiation of cartilage and bone from common germinal cells in vitro. Life Sci 1969;8:553-558.

46. Okubo $Y$, Bessho K, Fujimura K, Konishi $Y$, Kusumoto K, Ogawa $Y$, lizuka T. Osteoinduction by recombinant human bone morphogenetic protein-2 at intramuscular, intermuscular, subcutaneous and intrafatty sites. Int J Oral Maxillofac Surg 2000;29:62-66. 
47. Yoshida K, Bessho K, Fujimura K, Kusumoto K, Ogawa $Y$, Tani $Y$, lizuka T. Osteoinduction capability of recombinant human bone morphogenetic protein-2 in intramuscular and subcutaneous sites: An experimental study. J Craniomaxillofac Surg 1998;26: 112-115.

48. Gardin C, Bressan E, Ferroni L, Nalesso E, Vindigni V, Stellini E, Pinton P, Sivolella S, Zavan B. In vitro concurrent endothelial and osteogenic commitment of adipose-derived stem cells and their genomical analyses through comparative genomic hybridization array: Novel strategies to increase the successful engraftment of tissue-engineered bone grafts. Stem Cells Dev 2012;21:767-777.

49. Scherberich A, Muller AM, Schafer DJ, Banfi A, Martin I. Adipose tissue-derived progenitors for engineering osteogenic and vasculogenic grafts. J Cell Physiol 2010;225:348-353.

50. Supronowicz P, Gill E, Trujillo A, Thula T, Zhukauskas R, Ramos T, Cobb RR. Human adipose-derived side population stem cells cultured on demineralized bone matrix for bone tissue engineering. Tissue Eng Part A 2011;17(5-6):789-798.

51. Kim HP, Ji YH, Rhee SC, Dhong ES, Park SH, Yoon ES. Enhancement of bone regeneration using osteogenic-induced adiposederived stem cells combined with demineralized bone matrix in a rat critically-sized calvarial defect model. Curr Stem Cell Res Ther 2012;7:165-172.

52. Levi $B$, Nelson ER, Brown $K$, James AW, Xu D, Dunlevie R, Wu JC, Lee M, Wu B, Commons GW, Vistnes D, Longaker MT. Differences in osteogenic differentiation of adipose-derived stromal cells from murine, canine, and human sources in vitro and in vivo. Plast Reconstr Surg 2011;128:373-386.

53. Guven S, Mehrkens A, Saxer F, Schaefer DJ, Martinetti R, Martin I, Scherberich A. Engineering of large osteogenic grafts with rapid engraftment capacity using mesenchymal and endothelial progenitors from human adipose tissue. Biomaterials 2011;32:58015809.

54. Scherberich A, Galli R, Jaquiery C, Farhadi J, Martin I. Threedimensional perfusion culture of human adipose tissue-derived endothelial and osteoblastic progenitors generates osteogenic constructs with intrinsic vascularization capacity. Stem Cells 2007; 25:1823-1829.

55. Chai YC, Roberts SJ, Desmet E, Kerckhofs G, van Gastel N, Geris L, Carmeliet G, Schrooten J, Luyten FP. Mechanisms of ectopic bone formation by human osteoprogenitor cells on CaP biomaterial carriers. Biomaterials 2012;33:3127-3142. 